\title{
LA OBJETIVIDAD EN EL PROCESO PENAL ACUSATORIO*
}

\author{
Luis Rodrigo Fernández Portaluppi
}

Abogado

\section{SUMARIO:}

Introducción. I.- El principio de objetividad en la investigación del Ministerio Público. II.- La legitimidad del proceso penal. III.- El límite para conocer la verdad, un reconocimiento de nuestro Código Procesal Penal. IV.- El apogeo de los Derechos del Hombre. V.- El Proceso Penal Acusatorio imbuido en la cultura. VI.- La división de las facultades en el proceso penal: Los órganos y sus roles. VII.- La antinomia: La asignación de roles y separación de las funciones en contra de la objetividad. VIII.-La objetividad y su fuerza inquisitiva: Un incómodo legado del proceso penal inquisitivo para el proceso penal acusatorio moderno. IX.- Propuesta para entender a la objetividad en el proceso penal acusatorio.

\section{INTRODUCCIÓN:}

Los hombres se organizan de acuerdo a la visión que ellos tengan de sí mismos y del mundo que los rodea. Estas observaciones de sí y del entorno se hace desde el atalaya de sus creencias, construcciones forjadas a fuego en siglos de reflexión. Las creencias y las visiones del universo y de sí mismos son los elementos constitutivos de la cultura de un determinado grupo humano. De esta forma el Estado es una exteriorización de la visión de mundo, o dicho de otro modo, una materialización de las creencias humanas de una comunidad determinada pertenecientes a un tiempo y a un espacio también determinados. El Estado entonces es una manifestación cultural.

Pero la reflexión que el hombre hace de sí mismo y de su universo no se detiene. La cultura se transforma constantemente y sin descanso. De este modo tampoco se detienen las creencias desde las cuales se contempla el mundo. $Y$ si estas creencias cambian, entonces el mundo se transforma. Y lo que ayer parecía algo natural y obvio para una comunidad humana determinada, hoy se pone en duda, mañana se descarta, luego se olvida, y en el futuro, sin que la comunidad lo perciba fácilmente, lo vuelve a integrar a sus vidas como algo verdadero.

Este texto fue presentado en el Diplomado "La Reforma Procesal Penal: Aspectos Dogmáticos, legales y litigación en juicio oral". Realizado en la Escuela de Derecho de la Universidad Catolica del Norte, 2001. 
En este contexto, la historia ha registrado el levantamiento, transformación y caída de diversos tipos de organización Estatal (reinos, imperios, repúblicas, democracias y absolutismos, todos en sus más diversas formas y matices). De la mano a la organización del Estado se encuentran los sistemas jurídicos imperantes en cada lugar y tiempo. Especialmente sensible a las creencias que los hombres tienen de sí mismos y del medio circundante, y por tanto, a la forma que el Estado ha decidido utilizar para su organización (o mejor aún, a la forma como el Estado se relaciona con los individuos que conviven bajo su alero), son los sistemas procesales penales.

Los cambios (de creencias, de visiones de mundo, de Estados, en fin, de los sistemas penales y, específicamente, de los sistemas procesales penales) no se producen de un momento a otro como si lo antiguo dejase de existir para dar paso a lo nuevo que entra desde la nada, Los cambios son lentos. El objeto que sufre el cambio tiene una difusa frontera entre su antes y su después. Lo antiguo, en su camino de transformación, pasa por una etapa intermedia donde, en parte, convive (aveces extrañamente) con el futuro.

Esta tesis tratará algo más que un principio dentro del proceso penal acusatorio. Tratará de cómo un concepto cultural entra en el proceso penal para generar una u otra forma de aplicar la ley procesal. En el fondo tratará de cómo entre la cultura de una comunidad social y su proceso penal existe una vinculación más estrecha de lo que solemos pensar.

El principio de la objetividad de la investigación, que es de lo que trata este trabajo, es, según los fundamentos que se expondrán, extraño al sistema procesal penal acusatorio. Pero curiosamente, se le presenta como un principio de este mismo sistema procesal penal. Esto se traduce en un problema de coherencia dogmática, que, si no es bien enfocado desde la lógica del proceso penal acusatorio, puede traer efectos prácticos que desdibujen la arquitectura del proceso penal que se quiere construir, y nos empantane (al menos en parte) en aquella modalidad que se busca abandonar, el sistema procesal penal inquisitivo.

La situación de que un concepto propio del sistema inquisitivo se presente como un principio del sistema procesal acusatorio es producto de la asimilación cultural que implica la incorporación a nuestro orden jurídico de un proceso desarrollado principalmente en la cultura anglosajona.

El principio de la objetividad en la investigación se presentará, según se señaló, como un rasgo inquisitivo en un proceso acusatorio. Como un elemento completamente ajeno al sistema acusatorio. Se desarrollará una argumentación que demuestre como el principio entra en pugna con el nuevo sistema procesal penal que se intenta introducir. 
Finalmente, se propondrá una forma de entender o interpretar (si es que esto es posible), dentro de un sistema procesal penal acusatorio, al principio en cuestión.

La objetividad con que el legislador ordena que el Ministerio Público actúe, parece a simple vista de sanidad jurídica, una contención más a las fạcultades del órgano encargado de la investigación de la verdad histórica. De este modo, el legislador quiere que la objetividad se inserte en el proceso penal acusatorio como una racional garantía para el imputado (art. $19 \mathrm{n}^{\circ} 3$ inciso $7^{\circ}$ ), y como un elemento del derecho defensa. Sin embargo, esta tesis tratará de demostrar que esta forma de dar sanidad jurídica a la actuación del Ministerio Público es inútil, en el sentido que es sustituible por otros conceptos más acordes al proceso penal acusatorio (y que en el fondo ya se encuentran incorporados a él), y, por otra parte, entorpece los dogmas del sistema, pudiendo afectar, en el futuro, la ejecución práctica de este.

\section{I.- El principio de objetividad en la investigación del Ministerio Público.}

El principio de la objetividad esta establecido para la actuación del Ministerio Público y rige para determinar la forma y rumbo de la etapa de investigación. En estas condiciones podemos hablar de un principio objetividad dentro del Proceso Penal.

La objetividad se encuentra consagrado en el Código Procesal Penal (art. 77) y en la Ley Orgánica Constitucional Del Ministerio Público (art. 3). Sin embargo, este principio, o al menos el concepto, no alcanzó consagración Constitucional.

El artículo $3^{\circ}$ de la L.O.C del Ministerio Público explica, o intenta explicar, que es un criterio objetivo de investigación. Dice que investigar objetivamente es proceder con igual celo tanto en lo que perjudica como en lo que favorece al imputado, velando únicamente por la correcta aplicación de la ley.

Pero la introducción del concepto de objetividad tiene connotaciones que van mucho más allá de la definición del legislador. El diccionario de la Lengua Española, de la Real Academia, define en su primera acepción a la palabra objetivo como lo "Perteneciente o relativo al objeto en sí y no a nuestro modo de pensar o de sentir" ${ }^{1}$. De esta definición surgen inmediatas consecuencias, por ejemplo, el suponer que existe una realidad que está más allá de nuestro modo de pensar y de sentir.

Desde esta perspectiva no se entiende por qué el legislador incorporó el concepto de objetividad. Bastaba con que señalara que el Ministerio Público debe investigar con igual celo lo que perjudica y lo que beneficia al imputado ¿ para qué más?

1

Diccionario de la Lengua Española, Real Academia Española, 1984, vigésima edición. 
La objetividad trasciende al Ministerio Público y empapa a todo el sistema procesal penal. La investigación es un aspecto fundamental del proceso penal si consideramos que este, tiene por principal meta el entregar una forma de descubrir el pasado. Todo lo que se diga y haga de la investigación repercute en todo el proceso penal. Por esto decimos, y así será tratado a lo largo de la tesis, que la objetividad es un principio del proceso penal.

La objetividad también trasciende a la etapa de investigación. Si asumimos que la investigación que realiza el Fiscal es objetiva entonces no es razonable suponer que las demás actuaciones del Ministerio Público (la acusación por ejemplo) no tengan el mismo carácter. Una investigación objetiva tiñe de objetividad a todas las acciones de la Fiscalía. Por eso decimos que la objetividad está en todas las actuaciones del Ministerio Público y así será tratada a lo largo de esta tesis.

En gran medida todo lo que se señalará en esta tesis dice relación con las consecuencias de los conceptos (específicamente el de la objetividad) en el orden jurídico. La simple definición legal de las palabras no sirve para delimitar la carga cultural que arrastran producto de siglos de historia. En este caso veremos como el proceso penal es afectado por un concepto que escapa a cualquier control que el legislador pudiese establecer. Solo se puede contrarrestar esta fuerza si somos conscientes de la carga cultural e intervenimos en su contra.

Vayamos entonces por parte. Preguntémonos si, desde nuestra cultura jurídica pasada y presente (que es una porción de toda nuestra historia cultural) creemos o no en un mundo objetivo, es decir, un mundo que existe más allá de nuestros sentidos y pensamientos y si, aceptado ese mundo, estamos o no capacitados para conocerlo. $\mathrm{O}$, si por el contrario, creemos que el único mundo es el de nuestros pensamientos y sentidos.

\section{II.- La legitimidad del proceso penal.}

\section{El tema central del Proceso Penal.}

Todos los procesos judiciales, y especialmente el proceso penal, tienen como primer supuesto a los hechos. De la relación que haga el juez de estos con el derecho, emana una conclusión razonada que denominamos sentencia. Los hechos de que trata el proceso penal tienen la característica de ser una situación del pasado que se intenta reproducir en el presente.

El mayor problema del proceso penal es "como" se reconstruyen en el presente los hechos históricos que motivan el juicio, o, dicho de otro modo, la pregunta es 
"cómo" podemos conocer el pasado. La respuesta a esta pregunta, y por tanto, las características del proceso penal que la comunidad decida adoptar estará condicionada por su cultura. La comunidad siempre escogerá el proceso penal que, según las creencias y visiones de mundo y de sí mismo, parezca más perfecto para acercarse a la verdad que se quiere reproducir ante el juez. En fin, las formas procesales penales (las características de estas) están basadas en el "cómo" se traen los sucesos del pasado al presente.

La incertidumbre del hombre frente a los hechos históricos, que son absolutamente necesarios para aplicar el castigo penal, motivó la búsqueda de los instrumentos que pudiesen satisfacer la natural falta de conocimiento del pasado. La comunidad no tiene otra posibilidad que recurrir a su propia cultura para solucionar sus problemas. Por lo tanto, los instrumentos que llenarían el vacío del pasado son sacados de la cultura a la que pertenecen.

La legitimidad del proceso penal se encontrará en que la respuesta a la interrogante (¿Cómo podemos traer el pasado al presente?) se construya con aspectos culturales afianzados, o en vía de ello, dentro de la comunidad social en la que tiene cabida dicho proceso.

Según las bases culturales fundamentales de la legitimidad del proceso penal, hemos dividido a este en dos clases. La primera clase tiene como base cultural de la legitimidad del proceso penal a la autoridad del conocimiento absoluto del mundo. La segunda clase tiene como base cultural de la legitimidad del proceso penal a la autoridad de la convención de voluntades de los miembros de la comunidad. La primera clase da origen al sistema de ordalías e inquisitivo; la segunda, al sistema acusatorio.

\section{A) La autoridad del conocimiento absoluto del mundo como base cultural que da legitimidad al proceso penal.}

Esta base cultural responde a la pregunta del proceso penal señalando que sólo determinadas personas son capaces de descubrir el pasado. Ellas son aquellas que poseen el conocimiento. El proceso penal no descansa en un sistema propiamente tal, sino que en las personas dotadas de la autoridad del conocimiento. El conocer y el conocer un hecho determinado del pasado son sinónimos. Quién conoce como es el mundo puede interpretar correctamente los signos (las pruebas de los hechos) del mundo.

Esta clase de respuesta a la pregunta que hace el proceso penal (cómo traemos el pasado al presente), se enmarca en estadios culturales iniciales, cuando el conocimiento es reducido y, generalmente, en poder de pocas personas. Cuando el conocimiento es reducido, es decir, solamente existe un enfoque respecto del entorno, 
entonces hay lo que hoy llamaríamos objetividad. Si por el contrario el conocimiento se diversifica existiendo variados puntos de vista del mundo, entonces no es posible hablar de objetividad.

La objetividad tiene relación con una concepción de una realidad única, de la creencia de una verdad absoluta. Cuando la sabiduría de una época cabe en un solo estante, no hay conciencia de la complejidad del entorno. Un conocimiento reducido implica una simplificación que no es cuestionada, ser culto o tener el conocimiento implica observar al mundo desde la verdad de la época, es decir, objetivamente.

\section{Las ordalías:}

La primera respuesta sobre la pregunta del pasado (¿qué fue lo que ocurrió?) se le encomendó a aquel ser que tenía el conocimiento perfecto. Quién mejor que Dios para hacer justicia. Él todo lo sabe y, por tanto, la reconstitución del pasado estaba completamente asegurada.

\section{La Inquisición Religiosa:}

La expansión de un cristianismo más organizado, encabezada por la Iglesia Católica de Roma, y la auto atribución de esta de ser sustentadora de una Única y Verdadera Doctrina Sagrada, cambió las cosas radicalmente. La Iglesia Católica estaba integrada por hombres conocedores de la "Verdad Revelada" (manifestada en el libro sagrado, "La Biblia"), por lo tanto, era natural que la labor de buscar la verdad les fuera entregada a ellos (nace el proceso penal inquisitivo). Los "hombres de Dios", son santos y conocen la verdad (son estudiosos del libro sagrado). En su calidad de conocedores de la verdad, pasan a convertirse, por decirlo de algún modo, en la personificación de la verdad. Se abandona la abstracción de un juicio divino, para dar espacio a la materialización de la búsqueda del pasado en una persona.

Tanto en las ordalías como en el sistema inquisitivo religioso se pensaba que era posible alcanzar la verdad absoluta. En el primer caso era Dios mismo el que conocía la verdad y aplicaba la sanción penal; en el segundo caso sucedía de manera muy similar, sólo que ya no era Dios, en persona, sino que un "hombre de Dios" el que podía conocer y sancionar. 
En ambos tipos se trata de jueces justos o santos. Estos son rasgos de Dios y de los "Hombres de Dios"".

Según lo señalado no es extraño que en el sistema inquisitivo, el juez fuera considerado como apto para encontrar la verdad y juzgarla objetivamente. Respecto de lo primero, esto es, la posibilidad cierta de que el inquisidor encontrara la verdad histórica, sumado a la circunstancia que el proceso penal requería de hechos para ser juzgados, se terminó configurando el principio absoluto de la averiguación de la verdad.

\section{La Inquisición Monárquica.}

Con las monarquías absolutas, el poder penal paso a secularizarse. Si el inquisidor antes era un hombre de Dios, santo y conocedor de la única verdad; ahora era un hombre probo y culto. La legitimidad frente a la comunidad se mantuvo no obstante que el inquisidor dejó de ser un "hombre de Dios". Esto se explica porque en el fondo (en el ámbito conceptual) el cambio cultural es mínimo. En efecto, si al antiguo inquisidor le quitamos a Dios, tenemos un hombre culto (conocedor de la verdad) y probo (santo). Para los efectos de la legitimidad, la diferencia no era mucha entre el inquisidor eclesiástico y el monárquico. Y la diferencia es aún menor si consideramos que Dios, en las monarquías absolutas, se encuentra (directa o indirectamente) del lado del rey, quien en definitiva era el que, por la intermedio de los delegados, realmente impartía la justicia penal. Entonces los inquisidores monárquico también tenían algún respaldo divino.

El atributo de ser objetivo del inquisidor del absolutismo se debe, ya no tanto, a una delegación directa de Dios, sino principalmente a su calidad de hombre probo y culto. El conocimiento humano seguía siendo reducido. El saber oficial aún no se diversificaba y, por tanto, era perfectamente posible su concentración en una persona. El inquisidor era dueño de este conocimiento (el juez es "letrado") y, por tanto, podía apreciar las pruebas "objetivamente" (es decir, mediante el único punto de vista que representaba el reducido saber de la época) y conocer lo que realmente sucedió.

\section{Algunas reflexiones sobre el proceso penal inquisitivo:}

En el proceso penal inquisitivo (religioso y monárquico), la averiguación de la verdad histórica objetiva era alcanzable (como el conocimiento era reducido, se

\footnotetext{
${ }^{2}$ Creemos que la calidad de santo, también tiene que ver con la posibilidad de conocer. El puro, el santo o el justo es aquel que se encuentra libre de perturbaciones internas que le impidan apreciar los hechos de manera limpia. Lo mismo sucederá con el juez probo del proceso penal inquisitivo monárquico.
} 
desconocía la complejidad de la realidad), y necesaria (como en el fondo lo es en todo proceso penal), por lo tanto era bastante natural que la averiguación de los hechos fuera un fin absoluto. Conocer es sinónimo de conocer objetivamente (no hay más conocimiento que este).

En el sistema procesal penal inquisitivo la legitimidad se encontraba en la condición especial del inquisidor cómo un hombre dotado del conocimiento (primero gracias a su condición de santidad y conocedor de la verdad Revelada, luego por tratarse de un hombre culto y probo en quién el rey confiaba).

En el proceso inquisitivo el "como" se traen los hechos del pasado al presente se responde así: mediante aquellos que tienen el conocimiento. Quién sabe cómo es el mundo no comete errores al apreciar la prueba y al juzgar (algo así como "el que sabe no se equivoca"). Entonces el proceso inquisitivo descansa en los hombros de una persona (el inquisidor). No hay necesidad de defensa (que mejor defensa que el beneficio de que un hombre que sabe proceda a investigar y juzgar los hechos), no hay restricción para la averiguación de los hechos (el proceso es llevado adelante por una persona que posee el entendimiento suficiente como para nunca equivocar el camino, $y$, por otro lado, el casi ilimitado poder del inquisidor se justifica porque es posible y necesario encontrar la verdad histórica), la investigación es secreta (la falta de entendimiento de la comunidad la incapacita para tener acceso a ella), basta un solo hombre culto para conocer el pasado y castigar (no es necesario más, ya que todos los hombres cultos debieran llegar a la misma conclusión). Las más importantes características del proceso penal inquisitivo emanan de la circunstancia de que quién lo lleva adelante es un individuo particularmente sabio.

Con la dispersión del conocimiento, el sistema inquisitivo va perdiendo validez frente a los miembros de la comunidad. El eje de la legitimidad se desplaza, se comienza a creer que para conocer los hechos históricos es necesario algo más que un hombre dotado de conocimiento.

B) La autoridad de la reunión de las voluntades como base cultural que le da legitimidad al proceso penal.

En los tiempos modernos (desde la Revolución Francesa hasta nuestros días), el conocimiento ha perdido, paulatinamente, concentración individual y se transforma en patrimonio de la comunidad social. A la par se va desarrollando con cada vez mayor fuerza la especialización del saber. En definitiva, todos saben algo, pero algunos saben mucho sobre alguna cosa en especial. Se deslegitima lentamente al juez culto. Gradualmente se suprime la intervención personal del juez penal (aparece la prueba 
legal o tasada, y el principio de legalidad). El Juez es la boca muerta que pronuncia las palabras de la ley.

Los regímenes políticos se transforman. La democracia comienza a perfilarse como el régimen de Estado verdaderamente legítimo. La autoridad de los gobernantes no surge como consecuencia de alguna condición especial (generalmente divina), sino de la unión de las voluntades de los miembros de la comunidad. Hasta nuestros días, solo con algunas pequeñas distracciones, el camino de la humanidad ha sido la democracia, ella es reconocida internacionalmente como el sistema político verdaderamente legítimo.

Este cambio de eje de la legitimidad también se reflejó en los órganos (y funciones) encargados de la justicia. $O$ al menos así debió haber sucedido. En Hispanoamérica durante al menos dos siglos convivió un sistema judicial (especialmente el penal) propio de un régimen monárquico absoluto con una Constitución y un régimen político Republicano y Democrático.

Pensamos que la principal consecuencia de este desfase en la legitimidad es el desprestigio de la justicia institucionalizada. Es natural, los jueces no son considerados por la comunidad como conocedores de la verdad. La verdad es un bien inalcanzable o inexistente, incluso para los especialistas (aunque ellos son reconocidos, respecto de sus materias, como más cerca de ella). Por lo tanto, es imposible que un hombre (los jueces) se encuentren en condiciones de legitimidad suficiente como para decidir sobre como ocurrieron los hechos, y si el imputado merece o no una pena y cuál. La pregunta que surge entonces es ¿cómo se legitima la función judicial penal en un sistema democrático? o, en otras palabras ¿ cuáles son los elementos culturales que legitimarían la reconstitución del pasado?

Como ya se ha señalado, en tiempos del inquisidor la legitima respuesta a la pregunta de cómo reproducimos el pasado se encontraba en que había alguien que conocía la verdad del mundo. Pero en tiempos de democracia, con una comunidad cada vez más culta y con la disgregación del conocimiento, carece de sentido que la legitimidad de la acción penal mantenga su eje en la autoridad del conocimiento. Ya nadie puede atribuirse, de manera generalmente creíble, la facultad de conocer la verdad absoluta. Si la verdad absoluta la entendemos como la objetividad, podemos afirmar que, según los actuales parámetros culturales, nadie esta capacitado para ser objetivo. Por lo tanto lo que se busca es la mayor cantidad posible de información y esto se realiza recopilando y confrontando versiones, es necesario escuchar a todos los interesados y contrastar sus hipótesis.

En un régimen democrático, y en una sociedad cada día más culta, la legitimidad del sistema procesal penal no debe centrarse en una persona, sino que verdaderamente requiere de un sistema donde los actores que en él intervienen no 
necesitan de ninguna cualidad especial. El sistema se orienta a la acumulación y contraste de información, debidamente controlada por la comunidad social. La comunidad cree estar preparada para observar como se contrasta la información para reproducir el pasado. Ya nadie espera que se alcance la verdad absoluta, este es un bien ideal, imposible en su materialización. Solo se espera razonabilidad en la solución del conflicto penal. El estándar de razonabilidad debe ser encontrado en la valoración cultural de los antecedentes. Para que el sistema sea legítimo es necesario el control de la comunidad. En algunas naciones este control es directo, mediante la introducción de jurados. En otras, como es nuestro caso, el control toma la forma de un principio, el de la publicidad, tanto en la labor judicial, como en la del Ministerio Público.

Para los efectos de obtener la mayor información se separan las funciones (de investigar y juzgar) y se da un importante espacio en el proceso al defendido, mediante los derechos para la defensa. La investigación punitiva la tienen los órganos del Estado especializados en ella (el Ministerio Público y la Policía). Como la versión de los órganos de investigación punitiva no es absoluta (reconocido esto por la multiplicidad del conocimiento) se contrasta con la versión de la defensa que, mediante los derechos para la defensa, tiene un papel relevante dentro del debate. Como no hay una verdad es necesario el enfrentamiento de las verdades parciales (de la información). Para solucionar este conflicto de versiones, las hemos dispuesto ante el juez, pero bajo la mirada atenta de la ciudadanía (principio de publicidad).

Junto con la dispersión del conocimiento se agrega otro importante componente cultural al proceso penal acusatorio moderno, los denominados derechos del hombre. Los derechos del hombre son en el fondo un reconocimiento de la complejidad del mundo y de la dispersión del conocimiento. Si no existe una idea superior de cómo son o deben ser las cosas del mundo entonces nada justifica la provocación de dolor en el prójimo. Estos derechos se sumaron al reconocimiento de la dispersión del conocimiento y formaron el proceso penal acusatorio moderno.

Entonces, cuando al sistema procesal penal acusatorio moderno le preguntamos sobre cómo reconstruiremos los hechos del pasado, este responde: Acumulando información, contrastándola y juzgándola por la comunidad (mediante un jurado o mediante la mirada atenta de la comunidad-principio de la publicidad-). En definitiva nos encontramos con que la respuesta la entrega un verdadero sistema, y no una persona, como en el proceso inquisitivo puro. Pero a la respuesta de "cómo" podemos buscar el pasado en el presente, el sistema procesal penal acusatorio actual ha introducido otro condicionante cultural: el respeto por los derechos del hombre. 


\section{III.- El límite para conocer la verdad, un reconocimiento de nuestro Código Procesal Penal.}

Nuestro actual Código Procesal Penal se está encargando de legitimar la acción de la justicia penal. Para ello se aleja de la antigua creencia de que hay una existencia real del mundo que es independiente de las personas que son miembros de la comunidad. En este sentido el código procesal penal reconoce la limitación humana para conocer la verdad. Entonces el código reconoce que ninguna persona (ni siquiera el juez) se sustrae de esta limitación para conocer la verdad y, por tanto, el código admite que la legitimidad no puede descansar en un hombre culto. En otras palabras, el código procesal penal acepta que no es posible alcanzar la verdad absoluta respecto de los hechos históricos, y esto quiere decir que nadie esta en condiciones de conocer la verdad absoluta.

Podemos apreciar este reconocimiento en primer lugar porque el proceso se basa en el principio de la contradicción, es decir, el código supone que todos los actores del proceso penal tiene algo que decir, en otras palabras, a nadie se le atribuye la versión verdadera de los hechos. El enfrentamiento de las versiones arrojará luces respecto de qué fue lo que sucedió. Decimos que nos encontramos ante el examen de la información. Cada parte presenta su hipótesis (el Ministerio Público por un lado y la defensa por el otro) las que al contraponerse y ser revisadas recíprocamente darán señales que permitirá a los jueces decidir sobre la cuestión materia del juicio penal. Relacionado con el principio de contradicción nos encontramos con la separación de funciones (investigador y juzgador), con un órgano que concentra sus fuerzas en solamente investigar sin tener que auto- juzgar sus conclusiones (no se acepta como válido el auto control) y los derechos para la defensa (el imputado aporta en la reproducción del pasado).

En segundo lugar, decimos que el código procesal penal reconoce la imposibilidad de alcanzar la verdad absoluta, al otorgar las salidas alternativas. Es decir, alcanzar la verdad histórica dejó de ser un bien absoluto, porque no es posible (o al menos no siempre es posible), aunque continúa siendo un ideal que guía la acción. Las salidas alternativas descomprimen la tensión que existía para obtener lo que muchas veces era un imposible.

En tercer lugar, afirmamos que el código procesal penal reconoce la imposibilidad de llegar a una verdad absoluta, porque para condenar el estándar es, simplemente, que no exista duda razonable y exige para ello, sólo una convicción, no descubrir los hechos ${ }^{3}$. Se admite entonces algunas dudas, pero estas no deben afectar la

\footnotetext{
${ }^{3}$ Ver MAIER Julio, El Derecho Procesal Penal Argentino, Editorial Hammurabi, 1989, tomo I, pp, 562 y siguiente Él se refiere a la verdad con fuertes componentes sicológicos, la verdad no es independiente de las personas.
} 
convicción general a la que llegue y esta debe ser trascendente como para condenar. La inocencia, en cambio, no requiere convicción alguna y le basta la duda razonable. La convicción es una actitud sicológica y se refiere a un resultado de apreciación que la persona hace del mundo que le rodea. Esto supone aceptar que lo que sopese el juez sobre los hechos siempre será distorsionado por su propia condición humana.

En cuarto lugar, afirmamos que el código procesal penal reconoce que no es posible llegar a una verdad absoluta al reconocer las garantías individuales del imputado. La limitación al conocimiento de la verdad histórica absoluta es aceptada y respecto de ella se ha decidido, por un asurto político, favorecer al imputado. En otras palabras lo que desconoce de los hechos históricos, se presume que favorece al imputado. Entonces surgen el principio de inocencia (si no sabemos qué ocurrió presumimos que nada ocurrió), las restricciones a las medidas privativas de libertad, etc. Sobre este punto volveremos en unos capítulos más ${ }^{4}$.

Nosotros afirmamos que el código procesal penal reconoce que no se puede alcanzar nunca la verdad histórica absoluta, ni aún respecto de lo que pudiese interesar (los hechos que integran el tipo penal). Para esto tenemos una razón de texto: El código no pide lo imposible para condenar, la certeza; lo único que le basta es que sea razonable condenarlo, es decir, que no hubiese dudas razonables acerca de que realmente tenga responsabilidad en el delito. Además consideramos para ello un fundamento ontológico, cuando nos referimos a la verdad absoluta histórica nos referimos a ella en su aspecto esencial, y ciertamente que este no puede ser pedida por el legislador (antes esto era creíble, el inquisidor podía, con la ayuda de su conocimiento, llegar a una verdad histórica esencial o pura). Pero en todo caso podemos aceptar la opinión de que el código procesal penal sólo se refiera a que no siempre se puede alcanzar la verdad absoluta. Esto no tiene importancia para esta tesis toda vez que en ambos casos se admite que el hombre es incapaz o limitado para conocer la verdad histórica y es eso lo que nos interesa destacar.

\section{IV.- El apogeo de los derechos del Hombre.}

El siglo que recién pasó ha sido particularmente marcado por grandes y feroces guerras. Las armas utilizadas en este siglo han sido más poderosas que todas las armas juntas que la humanidad haya utilizado con anterioridad. Las personas que han muerto

\footnotetext{
En algunos casos, los derechos del imputado obedecen a razones fundamentalmente politicas, pero siempre estará presente nuestra aceptación de que ignoramos los hechos. En ocasiones no deseamos conocerlos (nos limitamos artificialmente), porque los instrumentos para acercarse a la verdad provocan un perjuicio mayor que el beneficio de encontrarla.
} 
o ha sido dañada a consecuencia de ellas hubiese implicado, en otros tiempos, terminar con la raza humana.

Pero no solamente ha sido la guerra la que ha provocado dolor a las personas de este siglo, las revoluciones internas de los países han aportado otro tanto. Nacionales luchando contra sus compatriotas despiadadamente.

La fuerza y cantidad de los horrores del siglo $X X$ son indescriptibles $e$ innumerables. La mayoría provocada por la contraposición de las visiones de mundo. En definitiva fue la intolerancia (especialmente la ideológica) la que mayormente contribuyó al desprecio de la vida. Los ideales de cada dogma superaban siempre al valor de la especie humana. El hombre era un instrumento de las políticas del Estado.

Frente al dolor se fue abriendo paso lentamente, como la única forma válida de relación entre las personas, y de ellas con los Estados (aún con independencia de la nacionalidad), el respeto a los derechos esenciales de los hombres. El valor de la especie humana, de las personas, creció frente a los fines de cada Estado nacional, hasta convertirse en un fin en sí mismo. Este es un elemento cultural muy fuerte de nuestro tiempo.

Como consecuencia de esta nueva actitud de la comunidad internacional, nacieron las numerosas declaraciones, convenciones, y legislaciones internas de las naciones, que se ocupan de proteger los derechos esenciales. La Declaración Universal de los Derechos del Hombre (1948); la Declaración Americana de lo Derechos y Deberes del Hombre (1948); La Convención Americana sobre los Derechos Humanos, también conocida como Pacto de San José de Costa Rica (1969); El Pacto Internacional de los Derechos Civiles y Políticos (1966); y La Convención (europea) sobre salvaguarda de los Derechos del Hombre y de las Libertades Fundamentales (1950) son los ejemplos más importantes de este nuevo rumbo emprendido por la historia. En nuestro derecho interno mención especial requiere el inciso $2^{\circ}$ del artículo $5^{\circ}$ de la C.P.E. que, sin entrar en un dabate más profundo, entrega el carácter de constitucional a los derechos del hombre.

Todo este movimiento en pos de la valoración de las personas, y que nos ha significado un fuerte círculo de protección y libertad, ha influido notablemente en la cultura $y$, por ende, en el proceso penal. Esto incluso se refleja con gran fuerza en el trabajo que actualmente se realiza para la creación de Cortes Penales Internacionales. 


\section{V.- El Proceso Penal Acusatorio imbuido en el mundo actual y en la dignidad del hombre.}

Como lo hemos expuesto en los capítulos anteriores el hombre actual vive en una cultura del conocimiento diversificado (por una parte desconcentración del saber que favorece a un número cada día más creciente de personas y por otra la especialización del conocimiento), también vive en (o más bien aspira a) una cultura democrática y respetuosa de los miembros de su especie. Estos son los elementos de creencias del entorno y de sí mismos y las visiones de mundo que determinarán en nuestro tiempo el "cómo" podremos reproducir el pasado en el presente en materia penal. En otras palabras, estos son los componentes culturales que fijarán las características de un proceso penal acorde a nuestro tiempo (legitimado ante la comunidad).

Entonces la reproducción de los hechos del pasado en el presente, mediante el sistema procesal penal acusatorio, reconoce la complejidad de la realidad y a ella le aplica una posición política determinada. En algunas oportunidades los intereses que surgen de la posición política coinciden con la frontera natural del conocimiento; en otras ocasiones, la frontera del conocimiento es instalada artificialmente para proteger los valores políticos adoptados.

Como ya se indicó, la posición política de gran parte del mundo es el respecto de los llamados Derechos Humanos. Es decir, el reconocimiento de los Estados de una esfera de protección casi totalmente inviolable. El poder penal del Estado puede invadir, hasta cierto punto, el círculo de protección cuando se dan las precisas condiciones previstas por el orden jurídico. Esta posición política sumada al reconocimiento de la complejidad del mundo (admitir que la ignorancia es una condición natural del hombre, y quizás su condición permanente) da como resultado las garantías del imputado en el proceso penal, una de los elementos importantes del proceso penal acusatorio moderno.

En algunas ocasiones ante la incertidumbre de la realidad del mundo, o dicho de otro modo, ante el reconocimiento de que no conocemos el pasado, se decide que la perplejidad favorezca al hombre. En otras ocasiones, la frontera del conocimiento del pasado se mueve artificialmente para favorecer el circulo de protección del imputado.

En todo caso, y tratándose del proceso penal, el círculo de protección surge principalmente del reconocimiento de la incertidumbre frente a los hechos del pasado, así decimos, por ejemplo, que el imputado debe ser tratado como inocente.

Algunas veces no hay ninguna posibilidad de conocer el pasado y este desconocimiento, por un asunto de decisión política, se entiende que debe favorecer al imputado. En otras, siempre frente a la incertidumbre del pasado, hay posibilidades de 
encontrar el conocimiento histórico, pero esta posibilidad, por un asunto de posición política, se decide eliminar optando por la ignorancia (En estos casos, la regla general es que el legislador le entregue la responsabilidad de decidir, directamente al juez). También nos encontramos frente al hecho de que el legislador admite la necesidad de obtener información (porque desconoce el pasado), y esto se ha traducido en la creación de los derechos de defensa del imputado.

Los derechos de defensa del imputado no quieren decir otra cosa que otorgarle al imputado un espacio real y efectivo dentro del proceso para que pueda aportar información acerca del pasado (datos de investigación e hipótesis de cómo ocurrieron los hechos). El sistema acusatorio supone que la información que del pasado pueda entregar una sola de las partes nunca será completa. Se admite entonces que la realidad se compone de enfoques $y$, por tanto, mientras el tribunal cuente con el mayor número posible de ellos (en realidad basta con las versiones que los interesados puedan traer) desarrollará con más tranquilidad su labor, sabiendo que se ha dispuesto con la mejor información del pasado que es posible de entregar (la que traen los interesados). En este contexto la actuación unilateral del Ministerio Público y sus órganos asesores (la policía) es insuficiente para alcanzar la visión más cercana a la verdad histórica. Para corroborar las informaciones es necesario filtrarlas recíprocamente. El Ministerio Público filtra la información de la defensa y la defensa hace lo mismo con la de él. En definitiva, producto de la perplejidad acerca de los sucesos del pasado, se le extiende al imputado una alfombra roja para que participe del proceso penal. Él tiene algo que nos puede servir para aclarar los sucesos pretéritos, tiene su versión de los hechos, tiene información. Nace así la necesidad de consagrar los derechos a la defensa. Mientras mejor sea la defensa mejor serán los resultados del juicio (del debate). Evidentemente que el Ministerio Público no puede quedarse atrás tampoco, debe haber igualdad en las fuerzas para la buena calidad del debate.

El principio de inocencia es también una decisión política frente a la limitación del conocimiento del pasado. La lógica es simple, si en el debate vence la duda, se decide por presumir que los hechos que desconocemos nos llevarian a la inocencia del imputado. La decisión política emana de la cultura (al menos teórica) del respeto a los miembros de la comunidad y, en general, de la especie. Si la política fuera, por ejemplo, la máxima seguridad de prevención de delitos, podría haberse optado, frente a la incertidumbre, por la culpabilidad ("no sabemos lo que ocurrió, pero es sospechoso que estés involucrado y como queremos prevenir los delitos a toda costa te condenamos"). Como se puede observar, la realidad de ignorancia (en el fondo se trata de una ignorancia por no alcanzar el convencimiento de conocer), no obstante un proceso penal acusatorio debidamente llevado, es la que nos obliga a enfrentarnos a una decisión política. En este caso el desconocimiento de los hechos del pasado es quien juega un rol preponderante y establece una institución clave dentro del proceso penal (esto sin dejar de desconocer la importancia de la decisión política). 
La postura ideológica de los Estados de Derecho es que la regla general sea el círculo de protección (derechos) de los ciudadanos. Esto sólo cambia en la medida que sea justificada la intrusión. El poder penal es, por regla general, la principal fuerza del Estado que puede penetrar la barrera de protección de los derechos. Con la sentencia condenatoria penal se restringen fuertemente estos derechos (la sanción penal es una restricción de derechos). La justificación a la invasión de los derechos individuales, es la existencia de un proceso penal en el que, en virtud del acopio de información debidamente examinada (referida al conocimiento del pasado), se alcanzó una razonable convicción de responsabilidad delictiva. La sociedad acepta que aquél responsable penalmente debe ser sancionado con algunas restricciones a sus derechos. La lógica es "no supiste utilizar tus derechos entonces te los limitamos a un mínimo".

Tratándose de las autorizaciones judiciales previas para las diligencias que pueden afectar los derechos de los imputados y la restricción a las medidas cautelares personales, nos encontramos frente a una zona gris. En este caso se desconoce la responsabilidad penal del imputado, sin embargo, algo se está diciendo de él. Hay una primera información que lo señala como imputado, esta única información no es suficiente. Como se trata de una zona gris el legislador no pudo establecer reglas inmutables (sólo algunos difusos estándar), y dejó al juez que decidiera según las circunstancias precisas del caso. El proceso penal da cautelosos pasos en busca de la verdad histórica, y esto porque hay un desconocimiento del pasado y no se quiere afectar el círculo de protección inútilmente. En el fondo, y por lo vago de los pocos estándar que entrega el legislador, la función de fijar la frontera del conocimiento la tiene el juez. El juez es el llamado a justificar la intrusión en los derechos del imputado no obstante la perplejidad frente a los hechos del pasado, y si la decisión es respetar los derechos deberá justificar la ignorancia (justificar la opción que significa no agredir los derechos del imputado, es decir, el desconocimiento). La justificación deberá basarse en los antecedentes que hasta ese instante se encuentren en su poder. Frente a la incertidumbre de los hechos, se le da al juez la facultad de tomar una postura política. Está en sus manos fijar el límite entre el conocer o ignorar en atención a las garantías que el Estado de Derecho le otorga al imputado. Como ya indicamos, las garantías que el Estado de Derecho otorga al imputado, surgen especialmente porque aún se desconocen los hechos (el juez deberá considerar esta circunstancia a la hora de trazar la frontera del conocimiento). Si el juez opta por los derechos del imputado y la abstención de buscar la verdad histórica entonces limita artificialmente la posibilidad de conocer. No es que no podamos conocer sino que preferimos no hacerlo fundado en las primeras informaciones (la contundencia de ellas), los bienes jurídicos en disputa (bienes jurídicos protegidos por el tipo penal y la esfera de protección del individuo que garantiza el Estado de Derecho) y el reconocimiento de que ignoramos los sucesos del pasado. Hablamos de una "zona gris" como metáfora de la ignorancia en que se encuentra el juez. La verdad es que en todo esto el juez va a tientas y en gran medida 
deberá confiar en su sentido común. El sentido común justificará (legitimará) la resolución que adopte frente a la comunidad. La comunidad espera del juez (y lo observa atentamente para fiscalizarlo) no que actúe con sabiduría, sino que con sentido común.

En definitiva podemos concluir que las garantías del imputado no sólo se han dispuesto por un asunto de postura ideológica. Tan importante como esta postura (y quizás más importante que ésta) es el establecimiento de estas garantías en virtud de admitir la incertidumbre de la realidad, en general, y del caso concreto en particular (la incapacidad de conocer los hechos del pasado). Nuevamente observamos como el juego del proceso penal, en general, se basa principalmente en la reconstrucción del pasado, o dicho de otro modo, el proceso penal es, fundamentalmente, una búsqueda del conocimiento.

\section{VI.- La división de las funciones en el proceso penal: Los órganos y sus roles.}

Como hemos indicado las características del proceso penal que se adopte dependen de la forma como una comunidad humana, determinada por sus creencias acerca del universo que los rodea y de sí mismos y sus visiones de mundo (en fin, determinada por su cultura), de respuesta a la pregunta de cómo se pueden traer al presente los hechos del pasado. Los componentes culturales de nuestro tiempo, y que han trascendido al proceso penal son, a nuestro juicio: la diversificación del conocimiento (una comunidad culta y el ingreso a la cultura de las especialidades del conocimiento) y los derechos humanos como única forma válida de relación entre los miembros de la comunidad y de ellos con el Estado. Nuestra cultura hispanoamericana ha respondido a la pregunta mediante la reciente inserción en nuestro sistema jurídico del denominado proceso penal acusatorio, y habría que agregar que este proceso penal acusatorio ha ingresado caracterizado por el respeto a los derechos consagrados para la especie humana. Este proceso penal es una forma de descubrir el pasado basado en un mecanismo, o sea, no importa una calidad especial de las personas que intervienen en el juicio (Fiscales, jueces y defensa). Este mecanismo se traduce en un debate (diversas informaciones en contradicción) enmarcado dentro del respeto de los derechos del hombre. En el proceso penal acusatorio el juicio es un debate.

El debate es la fórmula encontrada para el esclarecimiento de la verdad. Por lo tanto, si queremos encontrar la verdad debemos procurar establecer las mejores condiciones para que el debate se desarrolle óptimamente (sin dejar de considerar los derechos de las personas). En este contexto, con lo primero que debemos contar es que existan partes que tengan distintas hipótesis. En otras palabras, para que se presenten las versiones en el juicio es necesario que alguien las sostenga. Ese alguien debe tener un interés en presentar su hipótesis del caso. Es así como el proceso penal acusatorio ha 
creado, por un lado, un órgano público (Ministerio Público), interesado en la persecución penal, y, por el otro, ha cimentado los derechos que le permiten al imputado enfrentar en condiciones de equivalencia la pretensión de él (con un interés de contención de la fuerza penal pública).

La introducción de una persecución penal oficial produjo el órgano del Estado denominado Ministerio Público. Esta característica ha servido para señalar que el Ministerio Público no es parte del Proceso Penal acusatorio, pues su único interés sería el cumplimiento de la ley. Nosotros, sin deseos de ahondar en esta discusión, consideraremos al Ministerio Público como parte del proceso penal ${ }^{5}$, y es parte por la sencilla razón de que tiene un interés que quiere hacer efectivo dentro del Proceso Penal. Tiene una finalidad que debe alcanzar. Este interés (o finalidad), que obviamente es un interés publico y no privado, es la persecución penal respecto de los hechos constitutivos de delito (lo que implica la investigación de los hechos y el ejercicio de la acción penal si es procedente). Como el Ministerio Público tiene ese interés actúa, dentro del proceso penal, conforme lo dictan las necesidades de aquél, lo que generalmente se traduce en una oposición a los intereses de la defensa. Por otra parte, a pesar de ser un órgano del Estado, el Ministerio Público es autónomo, lo que significa que sólo debe responder a la lógica del mandato Constitucional y legal. En nuestro derecho el Ministerio Público tiene por finalidad primordial la persecución penal (su legitimidad frente a la comunidad dependerá si es observado o no como un organismo represor del delito) y en el camino para llevar adelante este cometido, como efecto secundario, necesariamente se encargará de velar por el cumplimiento de la ley, es decir, velar por la correcta actuación de la ley penal no es, ni debe ser, la principal preocupación de la Fiscalía. Esto es importante tenerlo en cuenta para poder señalar que el Ministerio Público tiene un interés absolutamente parcial, es decir, busca alcanzar una meta determinada. Si el interés del Ministerio Público fuese velar por la correcta actuación de la ley penal nos encontraríamos ante un interés abstracto que desvincularía al Ministerio Público de su rol.

En la lógica del proceso penal acusatorio, el grado de éxito en el descubrimiento de la verdad dependerá de la calidad del juicio, 0 , en otras palabras, del nivel del debate. Por otra parte, el debate dependerá en gran medida de la fuerza de los contenedores. Y la fuerza de ellos estará determinada en gran medida por el poder de concentración en sus roles. Es decir, el Ministerio Público debe concentrar sus fuerzas en la acción persecutoria penal y la defensa debe circunscribirse a su papel, que será principalmente el de contención de la actividad emprendida por la fiscalía (ambas

5 FONTECILLA RIQUELME, Rafael, Tratado de Derecho Procesal Penal, Editorial Juridica de Chile, 1978, tomo I, pp. 33. Señala que el proceso penal acusatorio se caracteriza por ser un proceso de partes. 
fuerzas se medirán en la arena del tribunal, ante el juez y la mirada atenta de la comunidad).

Si los actores desdibujan sus funciones, es decir, si no son capaces de enfocar su actividad dentro los límites naturales que emanan de los intereses que el proceso penal les exige, toda la estructura diseñada para el descubrimiento de los hechos se cae. Insistimos, el debate (la contradicción, el juicio) requiere actores que, dentro de sus papeles, desarrollen su actividad en contraposición. Si estos actores no actúan estrictamente desde las trincheras fijadas por el proceso penal acusatorio, no hay contradicción (no hay debate), es decir, no hay juicio $y$, por tanto, no hay descubrimiento de la verdad.

\section{VII.- La antinomia: La asignación de roles en contra de la objetividad.}

Ya hemos expuesto la importancia de que los actores se atengan estrictamente a sus roles (emanados de los intereses o finalidades que el proceso penal les asigna).

El principio de la objetividad establecido para la actuación del Ministerio Público (y por tanto para el funcionamiento del proceso penal) entorpece la necesidad de que este órgano del Estado se circunscriba a su papel Constitucional y legal. En efecto, la objetividad implica saltar desde el rol hasta una posición más allá de la parcialidad.

En la asignación de roles, el interés del Ministerio Público (la persecución penal) se materializa con una actividad destinada a convencer al juez de que la hipótesis de máxima culpabilidad es la que corresponde aplicar al caso. La defensa sostendrá exactamente lo contrario, su actitud de contención de la acción penal, irá destinada a obtener del juez una declaración de nula o mínima culpabilidad. Con este orden de cosas ¿ Cómo se puede pedir al Ministerio Público que actúe objetivamente si al mismo tiempo se le pide un compromiso político con la posición de máxima imputabilidad? ¿Es compatible el rol de persecutor de la responsabilidad penal con la exigencia de una actuación objetiva?, en otras palabras ¿Se puede ser "parte" y al mismo tiempo "objetivo?.

Para comenzar a dilucidar este asunto recurriremos a lo que el diccionario define por parte y por objetividad. Parte es definido como "Porción de un todo" y a la objetividad se la define en su segunda acepción como "imparcialidad" ${ }^{6}$. De la simple comparación de ambos conceptos definidos en el diccionario nos damos cuenta que la

6

Pequeño Larousse llustrado, Ramón García- Pelayo, edición 1987. 
objetividad (imparcialidad) es justamente lo contrario de parte (fragmento del todo; uno de los enfoques de los hechos del pasado).

El Ministerio Público ha establecido que solamente será objetivo hasta antes de acusar, y recién en ese momento, se inserta en su rol de persecutor dejando, por tanto, de ser objetivo. Es decir, se señala al principio de objetividad solamente como un principio que afecta a la investigación.

En nuestra opinión esta es una posición ingenua. Significa desconocer la fuerza de los conceptos culturales más allá de sus definiciones. Nos explicamos, si el Ministerio Público acusa, el tribunal deberá dar por sentado que la investigación fue objetiva (sino podría implicar una falta administrativa del fiscal, art. 49 L.O.C. del Ministerio Público). Si el tribunal estima que la investigación fue objetiva (que el fiscal hizo su trabajo como manda la ley) ¿qué pensará del debate?. ¿Realmente creemos que si la investigación es objetiva, el debate en juicio no estará también contaminado con el mismo concepto?. La investigación es la base de todas las otras acciones del Ministerio Público, por lo tanto, las características de ella son heredadas por todos los movimientos del órgano público. El concepto trasciende la definición. Para el juez le será imposible sustraerse del concepto aunque la definición legal lo limite a una etapa de actuación de la Fiscalía. El tribunal no dejará de considerar en el debate que una de las partes alguna vez fue objetiva. Esto es una desventaja enorme para la defensa y desequilibra las fuerzas produciendo una merma en el debate.

Por otra parte nos preguntamos lo siguiente ¿qué sucede si el fiscal pierde el juicio?. Entonces quiere decir o que desconoce el derecho o que no fue objetivo en la investigación. Sobre este último caso hacemos la pregunta. Que sucede si el fiscal fue diligente, aplicó correctamente la ley, pero en el debate, al ser apreciada las pruebas, el tribunal le da la razón a la defensa. Podemos decir realmente que el fiscal faltó al deber de objetividad de la investigación. Podemos sancionarlo por ello. Otra pregunta ¿creemos realmente en la objetividad cuando se trata de la vida práctica?.

La objetividad está cada día más desprestigiada cuando se trata de lo práctico. Pero puesta en el marco teórico, en el discurso, tiene una gran fuerza de dominación. De ahí la preocupación de que el fantasma de la objetividad ronde por el tribunal a la hora del debate. El debate es una reconstrucción del pasado, en esa condición se presenta en un plano teórico donde la objetividad tiene, en nuestra cultura, aún vigencia.

Por el otro lado el Ministerio Público no puede, ni aunque lo quisiera, entrar y salir de su papel. El proceso penal acusatorio moderno exige roles claros para un debate que permita reproducir el pasado. No es creíble que el órgano sea imparcial (objetivo) y luego, en determinada etapa, se haga cargo de su papel, o sea, se vuelva parcial. La 
comunidad social "no sabrá para quien trabaja" este órgano público, y verá como el órgano Estatal, creado para la persecución de los delitos, camina con rumbo ambiguo. Si el Ministerio Público no actúa con una identidad, con una clara finalidad, perderá legitimidad.

\section{VIII.- La objetividad y su fuerza inquisitiva: Un incómodo legado del proceso penal inquisitivo para el proceso penal acusatorio moderno.}

Hemos explicado como ser objetivo era necesario y razonable (en atención al entorno cultural) para el juez inquisidor. La objetividad significa para el inquisidor clásico, poseer el conocimiento. Al ser reconocido como válido un solo enfoque del mundo (el único conocido) el conocimiento era siempre objetivo (aunque la distinción entre lo objetivo y lo subjetivo es absolutamente moderna y desconocida para el inquisidor clásico).

Sin embargo se introduce en nuestro proceso penal acusatorio el principio de que el Ministerio Público debe actuar objetivamente en la investigación y al mismo tiempo que actúe dentro de su rol. Pero hemos visto que esto es imposible, que existe una contradicción total entre actuar objetivamente y actuar dentro de un rol o papel. Sin embargo al apreciar la actuación del Ministerio como objetiva trae varias consecuencias que perjudican la transición de un proceso inquisitivo a uno acusatorio. Sobre esto trataremos en este capítulo.

La primera consecuencia que imprime un carácter inquisitivo al sistema acusatorio y que resulta de considerar la actuación del Ministerio Público como objetiva, es que el debate deja de ser el elemento indispensable para reproducir el pasado.

En efecto, si el Fiscal actúa de acuerdo al principio de objetividad, es decir, ha investigado objetivamente $y$, por lo tanto, a acusado en conformidad a la investigación objetiva, en otras palabras, a acusado con una fuerte impronta objetiva, el juicio oral, el debate, pierde toda trascendencia. En esta lógica, la verdad histórica ha sido encontrada por la Fiscalía y ha sido presentada al juez. ¿ De qué sirve entonces la intervención de una contra parte? Si el juez cree que existió una investigación objetiva y que se ha acusado conforme a ella, no necesitará ninguna otra versión de los sucesos, ni más pruebas que las presentadas por el Ministerio Público. Por estas consideraciones es que podemos decir que si el Ministerio Público esta teñido por la objetividad, el proceso penal no requiere la aplicación del principio de la contradictoriedad, es decir, el tribunal debiera atender solamente lo presentado por el Fiscal objetivo.

Pero, siguiendo este derrotero, podemos avanzar a conclusiones aún más extremas. Si el tribunal, en atención a la objetividad con que actúa el Ministerio 
Público, falla, y debiera fallar siempre, dándole la razón (en verdad no podría hacerlo de otro modo porque el Ministerio Público actúa objetivamente, velando únicamente por la correcta aplicación de la ley penal) ¿qué sentido tiene la división de funciones?. Si se puede realizar una investigación objetiva y acusar con la impronta imborrable de la objetividad, qué finalidad tiene que un órgano del Estado investigue y el otro se ocupe de dictar sentencia. Con el ingreso del principio de la objetividad en la investigación de la Fiscalía, pierde sentido, al menos conceptualmente, la reproducción del pasado por medio de la confrontación, y pierde sentido la división de las funciones de investigar y de fallar en el proceso penal.

Pero también, con la introducción de la objetividad, carece de sentido los derechos de la defensa. Como se ha expuesto, el derecho de defensa tiene como una de sus funciones primordiales el establecerse como un elemento trascendente para el debate $y$, por tanto, como un elemento indispensable para la búsqueda de los hechos históricos. Según el sistema acusatorio los derechos de defensa otorgan una plataforma adecuada para que entre al juicio la versión del imputado $y$, en consecuencia, se produzca un debate valioso que permita reconstruir el pasado. Si la investigación es realizada por un órgano público objetivo, el principio de contradictoriedad se transforma en una fruslería, to que finalmente tiene como resultado que cualquier derecho de defensa es también inútil, carente de una finalidad seria.

Por último, si hay objetividad, en gran medida carecen de sentido la mayoría de los derechos humanos insertos en el proceso. Por ejemplo: Si el código Procesal Penal aceptara que es posible realizar una investigación objetiva, que sentido tendría el principio de inocencia. El investigador objetivo no necesita valerse de presunciones de ningún tipo, porque su visión exacta del mundo determinará la forma en que efectivamente ocurrieron los hechos. En el fondo el establecimiento de la objetividad, la mayoría de las veces, supondrá que es posible una realidad distinta de los sentidos y pensamientos humanos, y que esta se puede llegar a conocer. Desde esta perspectiva los derechos del imputado en el proceso ( $y$ los derechos humanos en general) son un obstáculo para alcanzar la verdad (o cualquier otra meta), La objetividad no consulta al hombre, porque no lo necesita.

De lo expuesto se puede apreciar que, al llevar a los extremos la aplicación de la objetividad, obtenemos como resultado ineludible a un sistema procesal inquisitivo. Pareciera que la conclusión fuera la siguiente: Mientras la objetividad ronde, hay bastante peligro de que el proceso penal nunca sea suficientemente acusatorio y que se retroceda con bastante facilidad al sistema procesal penal inquisitivo. A la inversa, si quitamos todo rastro de objetividad en un proceso penal las consecuencias lógicas será el desarrollo, tarde o temprano, de un sistema procesal penal acusatorio. 
Todo radica en nuestras creencias de nosotros mismos y del entorno, y como desde ellas vemos el mundo y actuamos conforme a él. Así por una parte si creemos en la existencia de una realidad inmutable, absoluta y verdadera entonces hablamos de objetividad y construimos un proceso penal que buscará reproducir esa verdad y, de este modo, tendrá cabida el sistema inquisitivo. Si por el contrario aceptamos una realidad cambiante, múltiple, compuesta de infinitas variables y puntos de vista entonces no podemos hablar de objetividad y construiremos un proceso penal que busque incorporar todos los puntos de vista y de este modo tendrá cabida el sistema acusatorio.

Para finalizar este capítulo citaré a Kirchheimer que nos ilustra sobre las consecuencias de la incorporación de conceptos puntuales (objetividad) más allá de los marcos teóricos en los que se insertan (proceso penal acusatorio): "Es de dudar que en la práctica procesal alemana haya existido alguna vez un auténtico equilibrio entre la defensa y la acusación. De algún modo, a pesar de su posición teórica como funcionario del tribunal, el abogado particular nunça podrá competir con el prestigio del fiscal, representante de la oficina más objetiva del mundo, como se le denominaba en el lenguaje oficial" ${ }^{7}$

\section{IX.- Propuesta para entender a la objetividad en el proceso penal acusatorio.}

Hasta aquí, y a lo largo de todo este trabajo, nos hemos explayado sobre la gran carga conceptual inquisitiva de la palabra "objetividad". La pregunta que debemos responder ahora es ¿ Cómo la podemos entender dentro del proceso penal acusatorio?.

Esta de más indicar que lo ideal sería erradicar todo vestigio de objetividad del proceso penal. Las supuestas salvaguardas que teóricamente significa para el imputado la objetividad, se encuentran en otros conceptos más precisos y ya incorporados en el sistema acusatorio. La inclusión de la objetividad nada aporta $y$, por el contrario, entorpece la transición a un proceso penal verdaderamente acusatorio, adaptado a los patrones culturales de nuestro tiempo y, por lo tanto, a un proceso penal dotado de legitimidad frente a la comunidad.

Pero asumiendo el concepto de la objetividad como incorporado al sistema (C.P.P. y L.O.C del M.P.), producto de la propuesta del C.P.P. modelo para Latinoamérica, debemos tratar de identificar cual podría ser su función en el contexto de un proceso penal acusatorio moderno.

7

KIRCHHEIMER, Otto, Justicia Política (trad. R. Quijano) pp.301, $1^{\circ}$ ed. 1968. Citado por Rusconi, Maximiliano, División de poderes en el proceso penal e investigación a cargo del Ministerio Público, pp. 102. 
Para interpretar a la objetividad en el contexto de un proceso penal acusatorio debemos hacernos la siguiente pregunta ¿Qué es lo que se podría esperar de la actuación del Ministerio Público en su fase de investigación?. Quizás en primer lugar señalemos que queremos a un Ministerio Público que respete a los derechos de las personas. En segundo lugar la respuesta más sencilla, dentro de nuestra cultura hispanoamericana, fuertemente imbuida por el sistema inquisitivo ( $y$ tal vez aún con rasgos de una mentalidad monárquica y jerarquizada), podría ser la petición de que la actuación fuese objetiva.

La objetividad se señala como una fórmula de protección, es decir, si el Ministerio Público es objetivo no podrá ser arbitrario en sus acciones. Pero un principio de objetividad, que es solo un texto, no resguarda de posibles actuaciones arbitrarias de la Fiscalía. El verdadero resguardo del imputado frente a la arbitrariedad es todo el sistema acusatorio: el control judicial a la investigación, el derecho de defensa, etc., pero el principal resguardo es el debate (la contradicción). Si el Ministerio Público es arbitrario su pretensión no prosperará frente a un debate en igualdad de armas, pero si el debate se produce frente a un órgano que se atribuye objetividad ciertamente que el imputado estará en desventaja.

Las condiciones que podemos exigir a la investigación de la Fiscalía deben ser conceptos lo más precisos y prácticos posible. Las aspiraciones teóricas o idealistas, por su falta de claridad, nunca serán las mejores contenciones a las pretensiones del Ministerio Público.

Para descubrirlas buscaremos dentro de las garantías Constitucionales. Estas establecen el derecho a una racional y justa investigación (art. $19 n^{\circ} 3$ inciso $7^{\circ}$ ). La racionalidad de la investigación debe dirigirse fundamentalmente a aquellos aspectos que son esenciales para que la contienda sea equivalente, para mejorar el debate, para acercarnos a la verdad histórica. Dentro de los derechos de defensa del imputado, se encuentran ciertas exigencias al Ministerio Público (C.P.E.; L.O.C. M.P.; C.P.P.) que son absolutamente necesarias para ello.

En primer lugar, que el imputado conozca los antecedentes que, producto de la investigación, el Ministerio Público ha logrado recolectar. De esta forma podrá conocer la base de la acción del Ministerio Público y preparar una adecuada defensa. $Y$ en segundo lugar, que la investigación sea completa, es decir, que se haya investigado en todos sus aspectos los hechos que se intentarán reproducir en el juicio. Este punto es muy importante, ya que la supremacía de la investigación la tiene la Fiscalía y el poder penal le entrega importantes facultades que le permiten llegar con la investigación más allá de lo que podría hacerlo el imputado. 
En definitiva ambos elementos enunciados podrían englobarse en el concepto de un "juego limpio" del Ministerio Público, es decir, que el órgano de la investigación actúe con honradez. En el fondo, no parece que nada más, ni nada menos, que probidad es lo que se le puede, y debe, exigir.

Podríamos hablar entonces de un principio de probidad en la actuación del Ministerio Público. Y este principio de probidad estaría compuesto de dos elementos concretos: La publicidad relativa de la investigación (solamente para los intervinientes); y la investigación completa (tanto de los elementos que perjudican como los que favorecen al imputado). El primer elemento es regla general y, en esas circunstancias, se encuentra con pequeñas excepciones que no empañan el principio de probidad; el segundo elemento que constituye al principio de probidad del Ministerio Público es absoluto, la investigación debe ser completa (solamente con la limitación propia de nuestra naturaleza humana).

La objetividad, realmente nada tiene que ver con los dos elementos de la probidad y más aún, estos elementos se encuentran consagrados dentro de nuestro sistema penal acusatorio.

Como se advierte, la objetividad nada aporta a un sistema acusatorio, en cambio un principio de probidad de la investigación, sí. El principio de probidad cuenta con los dos mencionados elementos, estos se refieren a una forma precisa de llevar la investigación, y ahí se agotan. Son concretos y simplemente facilitan la defensa, y en consecuencia mejora el debate.

La propuesta sería que al denominado principio de objetividad se lo interprete como el principio de probidad de la investigación.

Sin embargo insistimos, lo verdaderamente sano sería eliminar definitivamente todo rastro de objetividad en el nuevo proceso penal acusatorio. Con esta eliminación nada se pierde, pero si se gana y mucho. Se da un salto más decidido a un proceso penal acusatorio con mayor legitimación. 